\title{
Paramount Impact of the Indian Ocean Dipole on the East African Short Rains: A CGCM Study
}

\author{
Swadhin K. Behera, Jing-Jia Luo, and Sebastien Masson \\ Frontier Research Center for Global Change/JAMSTEC, Yokohama, Japan \\ Pascale Delecluse \\ Laboratoire d'Océanographie Dynamique et de Climatologie, Paris, and Laboratoire des Sciences du Climat et de l'Environnement, \\ Orme, France \\ Silvio Gualdi And Antonio Navarra \\ Istituto Nazionale di Geofisica e Vulcanologia, Bologna, Italy \\ Toshio Yamagata \\ Department of Earth and Planetary Science, University of Tokyo, Tokyo, and Frontier Research Center for Global Changel \\ JAMSTEC, Yokohama, Japan
}

(Manuscript received 7 September 2004, in final form 4 May 2005)

\begin{abstract}
The variability in the East African short rains is investigated using 41-yr data from the observation and 200-yr data from a coupled general circulation model known as the Scale Interaction Experiment-Frontier Research Center for Global Change, version 1 (SINTEX-F1). The model-simulated data provide a scope to understand the climate variability in the region with a better statistical confidence. Most of the variability in the model short rains is linked to the basinwide large-scale coupled mode, that is, the Indian Ocean dipole (IOD) in the tropical Indian Ocean. The analysis of observed data and model results reveals that the influence of the IOD on short rains is overwhelming as compared to that of the El Niño-Southern Oscillation (ENSO); the correlation between ENSO and short rains is insignificant when the IOD influence is excluded. The IOD-short rains relationship does not change significantly in a model experiment in which the ENSO influence is removed by decoupling the ocean and atmosphere in the tropical Pacific. The partial correlation analysis of the model data demonstrates that a secondary influence comes from a regional mode located near the African coast.

Inconsistent with the observational findings, the model results show a steady evolution of IOD prior to extreme events of short rains. Dynamically consistent evolution of correlations is found in anomalies of the surface winds, currents, sea surface height, and sea surface temperature. Anomalous changes of the Walker circulation provide a necessary driving mechanism for anomalous moisture transport and convection over the coastal East Africa. The model results nicely augment the observational findings and provide us with a physical basis to consider IOD as a predictor for variations of the short rains. This is demonstrated in detail using the statistical analysis method. The prediction skill of the dipole mode SST index in July and August is $92 \%$ for the observation, which scales slightly higher for the model index (96\%) in August. As observed in data, the model results show decadal weakening in the relationship between IOD and short rains owing to weakening in the IOD activity.
\end{abstract}

\section{Introduction}

The seasonal rainfall in the equatorial eastern Africa is characterized by double peaks. This semiannual sig-

Corresponding author address: Toshio Yamagata, Frontier Research Center for Global Change/JAMSTEC, Showa-machi, Yokohama, Kanagawa 236-0001, Japan.

E-mail: yamagata@eps.s.u-tokyo.ac.jp nal is basically related to the seasonal meridional migration of the intertropical convergence zone across the equator (Fig. 1). The two peaks are often referred to as long and short rains. Amount of rainfall is larger during the season of long rains from April through May, as compared to that of the short rains from October through November (e.g., Hastenrath et al. 1993). This is explained by the persistent cold sea surface temperature (SST) in the western Indian Ocean during the lat- 

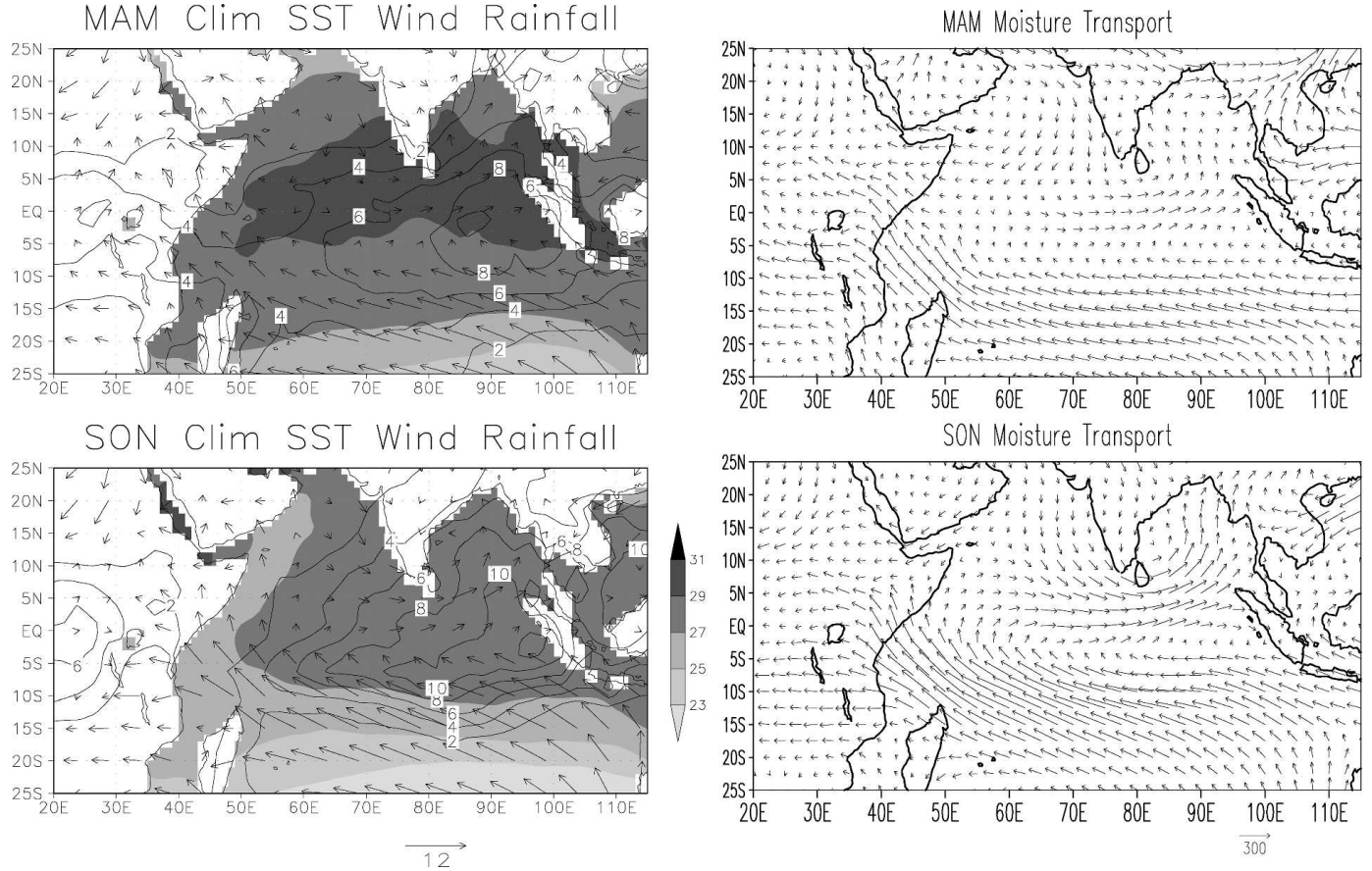

FIG. 1. (left) SST climatology (shaded), surface wind, and rainfall (contoured) for Mar-May and Sep-Nov seasons. SST fields are derived from GISST data and wind fields are derived from NCEP-NCAR reanalysis data. The rainfalls are derived from Climate Prediction Center (CPC) Merged Analysis of Precipitation data. Unit for SST is ${ }^{\circ} \mathrm{C}$, for wind is $\mathrm{m} \mathrm{s}^{-1}$, and for rainfall is $\mathrm{mm} \mathrm{day}^{-1}$. (right) Tropospheric moisture transports $\left(\mathrm{kg} \mathrm{m}^{-1} \mathrm{~s}^{-1}\right)$ for the corresponding seasons.

ter season (Fig. 1) after the active coastal upwelling due to the boreal summer monsoon. The surface winds are easterlies south of the equator in the eastern and central Indian Ocean but veer northwestward toward East Africa during both transition seasons. The regional veer coincides with development and retreat of the boreal summer monsoon and leads to moisture convergence over East Africa, enhancing the atmospheric convection and rainfall there. Although the averaged rainfall amount is larger during the long rains than during the short rains, the latter show more interannual variability (Hastenrath et al. 1993; Black et al. 2003; Clark et al. 2003) and have a larger impact on the society through changes of the regional hydrological cycle. Therefore, we discuss here the variability of the East African short rains (hereafter referred to as short rains) using results from a 200-yr coupled model simulation as well as observational data.

Earlier studies have attempted to link the variability in the tropical Pacific Ocean to the rainfall variability of the region (Ropelewski and Halpert 1987; Ogallo 1988; Ogallo et al. 1988; Hastenrath et al. 1993; Mutai and Ward 2000). It has been generally believed that the short rains increase (decrease) during the warm (cold) El Niño-Southern Oscillation (ENSO) events. In an earlier study Hastenrath et al. (1993) found that the causality of short rains anomalies are strongly related to the Southern Oscillation (SO), that is, the atmospheric component of ENSO. Based on the analyses of available observed data, they suggested that during high SO phase the pressure is high (low) in the western (eastern) Indian Ocean during October-November. Concomitantly they also found that strong westerlies sweep the equatorial zone of the basin, and the surface waters in western Indian Ocean that are cold suppress the atmospheric convection. In a negative SO phase the oceanatmosphere condition becomes opposite, and western Indian Ocean and the East African region receive abundant precipitation. This hypothesis contributed to deepening of our appreciation of the simultaneity of some ENSO events and floods and droughts associated with the short rains but failed to provide a unified viewpoint that can explain all the extreme events as acknowledged in Hastenrath and Polzin (2003). Recent studies report some of these exceptional short rains events (Saji and Yamagata 2003b; Black et al. 2003; Behera et al. 2003a; Yamagata et al. 2004). One typical case is the record-breaking floods in 1961, which did not coincide a negative SO phase. During that year, the Pacific condition was quite normal but the Indian Ocean condition was reportedly abnormal (Reverdin et al. 1986). The unique variability in the Indian Ocean 

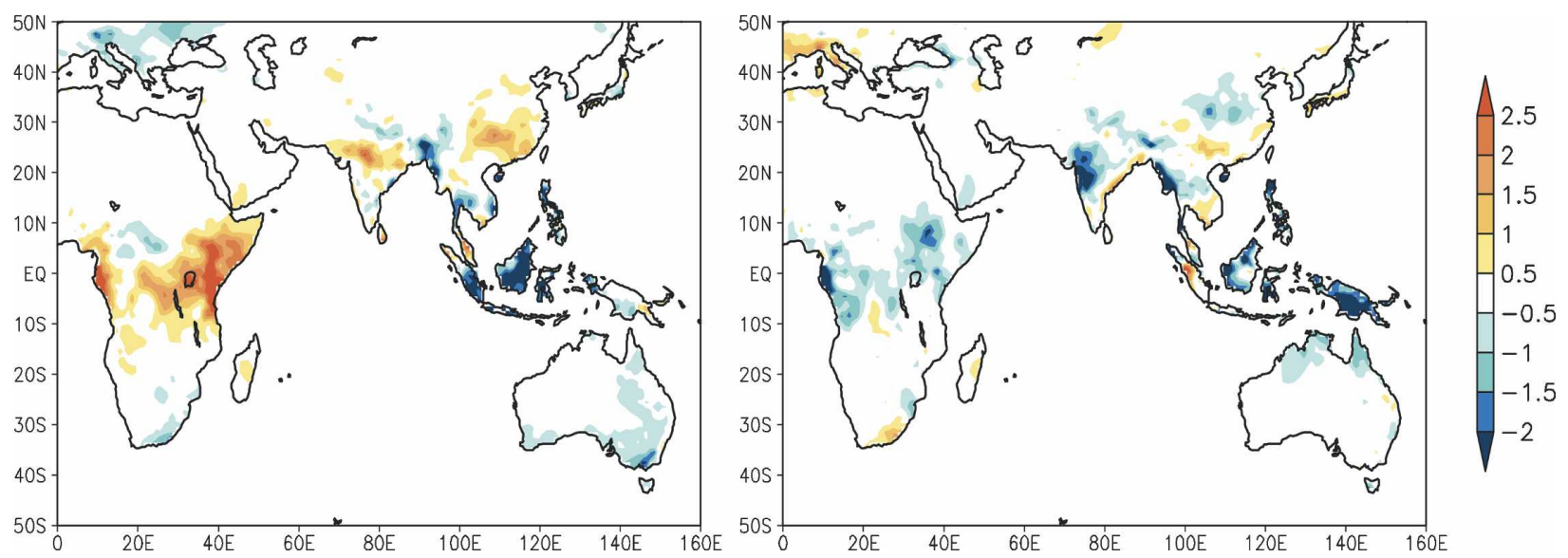

FIG. 2. Composite rainfall anomalies in $\mathrm{mm} \mathrm{day}^{-1}$ for Sep-Nov during (left) pure IOD and (right) pure ENSO events. The rainfall anomalies for the period 1958 to 1999 are derived from University of Delaware gridded precipitation analysis. The independent years used in the composites of pure IOD and pure ENSO are taken from Yamagata et al. (2004).

has recently been reorganized as an inherent oceanatmosphere coupled mode (e.g., Saji et al. 1999; Webster et al. 1999; Yamagata et al. 2003, 2004), which is now widely accepted as an Indian Ocean dipole (IOD) mode. In view of this new mode, the focus has been shifted to the Indian Ocean for understanding variability of the short rains (Saji and Yamagata 2003b; Black et al. 2003; Behera et al. 2003a; Clark et al. 2003; Yamagata et al. 2004).

Saji et al. (1999) showed that an east-west dipole mode in the sea surface temperature (SST) anomalies of the tropical Indian Ocean is coupled to the surface zonal winds. They also showed that the SST dipole is significantly correlated with the rainfall variability over the two poles. The rainfall over East Africa (Indonesia) is increased (decreased) during a positive event. Consequently, recent studies tried to compare the fractional influence of IOD and ENSO on short rains (Saji and Yamagata 2003b; Black et al. 2003; Clark et al. 2003; Behera et al. 2003a). In Fig. 2, we show the relative influence of IOD and ENSO on short rains using the independent composite method adopted by Saji and Yamagata (2003b) and Yamagata et al. (2004); we find that the IOD influence is very significant on the variability of short rains. The East African region receives above (below) normal rainfall during positive (negative) IOD events. Comparatively the ENSO influence in that region is quite different from a conventional view. Once we remove the IOD influence from the composite, the pure ENSO influence becomes even opposite in East Africa (cf. Saji and Yamagata 2003b; Yamagata et al. 2004); El Niño (La Niña) produces a negative (positive) anomaly in short rains. Quite interestingly, this contrasts with Clark et al. (2003).

The recent finding about the relative influence of
IOD and ENSO on short rains is not surprising. About $30 \%$ of positive IOD events co-occur with El Niño events (Rao et al. 2002). It is noticed that this percentage of co-occurrences varies marginally depending on SST data products. Nevertheless, we found that the percentage of IOD events independent of ENSO is always higher than that of the percentage of co-occurrences irrespective of SST dataset. The statistical analyses reported prior to the introduction of the IOD mode did not recognize this degeneracy of two climate modes. Therefore, those analyses inherit part of the IOD influence on short rains as an apparent positive relation between ENSO and short rains. Even the cooccurrence of IOD and ENSO (e.g., as in 1997) does not necessarily suggest that ENSO influences short rains through IOD. This is because the IOD can evolve independently of the ENSO as in 1961, 1967, and 1994 (Saji et al. 1999; Webster et al. 1999; Anderson 1999; Yamagata et al. 2002, 2003, 2004; Behera et al. 2003b; Saji and Yamagata 2003a). Unlike the basinwide surface warming (cooling) that is related to warm (cold) ENSO, the dipole mode is rooted in subsurface equatorial ocean dynamics (e.g., Murtugudde et al. 2000; Rao et al. 2002; Rao and Behera 2005; Feng et al. 2001; Shinoda et al. 2004) and appears to be inherent in the Indian Ocean. Recent teleconnection studies also reveal the unique influence of IOD on many parts of globe (Ashok et al. 2001; Guan and Yamagata 2003; Saji and Yamagata 2003b; Zubair et al. 2003; Yamagata et al. 2004). Therefore, it is natural to expect that the IOD has a significant influence on the neighboring East Africa. In light of this, we investigate the IOD-short rains relation using 200-yr simulation results from a coupled general circulation model (CGCM), which simulates IOD and ENSO events rather realistically. In 
particular, we examine the mechanism proposed by Hastenrath et al. (1993). It is shown that the long time series data from the model corroborate the recent observational finding about the influence of IOD on short rains.

\section{Model and data}

The CGCM used in the present study is known as scale interaction experiment-Frontier Research Center for Global Change, version 1 (SINTEX-F1) and is an upgraded version (see Masson et al. 2005; Luo et al. 2003) of the SINTEX model described in Gualdi et al. (2003). The model is also adapted for use of the Earth Simulator. In the present CGCM, the atmospheric component ECHAM-4 (Roeckner et al. 1996) is fully coupled to the ocean component océan parallélisé (OPA8.2; Madec et al. 1998) through the oceanatmosphere-soil-ice system coupler (OASIS) 2.4 (Valcke et al. 2000). The atmosphere model has a spectral representation in the horizontal with a triangular truncation at wavenumber 106 (T106) and has 19 discrete vertical levels. This spectral resolution is roughly equivalent to a horizontal grid mesh of $1^{\circ} \times 1^{\circ}$. The ocean model OPA8.2 adopts the Arakawa $\mathrm{C}$ grid with a finite mesh of $2^{\circ} \times 0.5^{\circ}$ cosine (latitude); the meridional grid resolution increases toward the equator with a grid length of $0.5^{\circ}$ in the equatorial region. To avoid the singularity in the coordinate system, the finite mesh is designed in a way such that the North Pole is replaced by two nodal points located over North America and Eurasia. The model has 31 levels in the vertical. The details of the coupling strategy are reported in Guilyardi et al. (2001) and the model skill in reproducing the Indian Ocean variability is found in Gualdi et al. (2003) and Yamagata et al. (2004). The monthly data from the last $200 \mathrm{yr}$ of the total 220 -yr model results are used in the present analysis.

In addition to the 220-yr-long control experiment, we performed an additional model experiment in which the interannual air-sea interaction is suppressed in tropical Pacific by decoupling the ocean and atmosphere in that region. In this decoupling procedure climatological SSTs between $25^{\circ} \mathrm{N}$ and $25^{\circ} \mathrm{S}$, instead of interannual SSTs, derived from the last 200-yr result of the control experiment are supplied to the atmospheric model as the lower boundary condition. In this way, we suppress the ENSO evolution in the coupled model while allowing the independent evolution of IOD: this 70 -yr decoupled experiment is aptly named as the noENSO experiment.

The observed data used in the analysis are from 1958 to 1999. Monthly anomalies of atmospheric fields are derived from the National Centers for Environmental
Prediction-National Center for Atmospheric Research (NCEP-NCAR) 40-yr reanalysis data (Kalnay et al. 1996). SST anomalies are computed from the Global Sea Ice and Sea Surface Temperature (GISST) 2.3b dataset (Rayner et al. 1996); other ocean variables like the sea surface height and heat content are derived from the simple ocean data assimilation (SODA) products (Carton et al. 2000). The rainfall anomalies for the period 1958 to 1999 are derived from University of Delaware gridded precipitation analysis. Using the statistical technique described in Willmott and Matsuura (1995), the University of Delaware team has interpolated the precipitation data from a large number of stations, both from the Global Historical Climate Network and more extensively from the archive of Legates and Willmott (1990), to regular $1 \times 1$ grids. The time series spans from 1950 to 1999 of monthly mean surface air temperatures, and monthly total precipitation. It is land-only in coverage, and complements the Comprehensive Ocean-Atmosphere Data Set (COADS) well. Following Saji et al. (1999), the dipole mode index (DMI) is defined as the SST anomaly difference between the western $\left(10^{\circ} \mathrm{S}-10^{\circ} \mathrm{N}, 50^{\circ}-70^{\circ} \mathrm{E}\right)$ and eastern $\left(10^{\circ} \mathrm{S}-0^{\circ}, 90^{\circ}-110^{\circ} \mathrm{E}\right)$ tropical Indian Ocean. The western box $\left(10^{\circ} \mathrm{S}-10^{\circ} \mathrm{N}, 40^{\circ}-60^{\circ} \mathrm{E}\right)$ of model DMI is slightly westward of that in observed data. The zonal wind index is derived as in Saji et al. (1999) from the area average over the domain $5^{\circ} \mathrm{S}-5^{\circ} \mathrm{N}$ and $70^{\circ}-80^{\circ} \mathrm{E}$ for both model and observed data. The observed Niño-3 index is derived from the GISST data. We define an index for short rains by averaging the gridded precipitation data over the area $\left(5^{\circ} \mathrm{S}-5^{\circ} \mathrm{N}, 35^{\circ}-46^{\circ} \mathrm{E}\right)$.

Besides simple linear statistical tools such as a composite technique and a correlation method, a partial correlation technique (e.g., Yule 1907) is used to show a partial relationship between three variables. For example, the partial correlation between DMI and precipitation anomalies, while excluding the influence that arises owing to correlation between Niño-3 and precipitation anomalies (cf. Saji and Yamagata 2003b; Yamagata et al. 2004), is defined as follows:

$$
r_{13,2}=\left(r_{13}-r_{12} \cdot r_{23}\right) / \sqrt{ }\left(1-r_{12}^{2}\right) \bigvee\left(1-r_{23}^{2}\right),
$$

where $r_{13}$ is the correlation between DMI and precipitation anomalies, $r_{12}$ is the correlation between DMI and Niño-3 index, and $r_{23}$ is the correlation between Niño-3 and precipitation anomalies. Similarly, the partial correlation is obtained for Niño-3 and precipitation anomalies while excluding the influence due to the correlation between IOD and precipitation anomalies. Statistical significance of the correlation coefficients is determined by a two-tailed $t$ test. To focus on interannual 

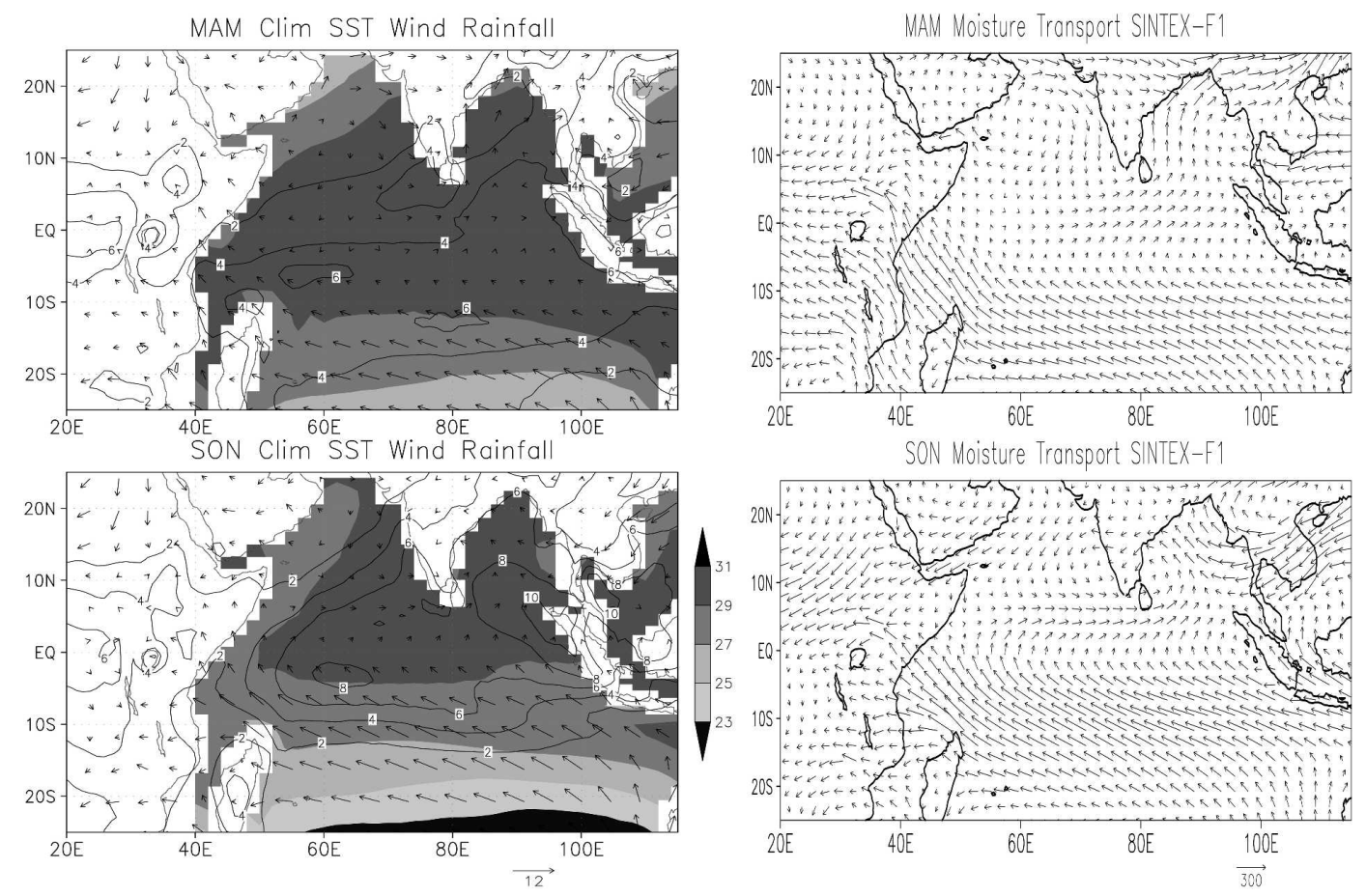

FIG. 3. Same as Fig. 1 but for SINTEX-F1 simulation results.

variations, low-frequency variations whose periods are longer than 7 are removed from all the datasets with a high pass filter (Butterworth filter).

\section{Model climatology}

The model climatology is described here for two transition seasons of boreal spring and fall before discussing simulated interannual variations. The climatology of the SST, wind, rainfall, and moisture shown in Fig. 3 are compared with that of the observation shown in Fig. 1. Overall features of the model climatology are comparable with those of the observations. The seasonal characteristics of SST, wind, and rainfall are captured well by the SINTEX-F1 model. The seasonal moisture transport as simulated by the model also agrees very well with the observed transport. However, there is a clear model bias near the African coast; the SST in the region is warmer than the observation. During boreal fall the difference is about $1^{\circ} \mathrm{C}$. This model bias is quite common in coupled models and is due to weaker coastal upwelling. An intercomparison study of model results with other coupled models is in progress not only to reduce but also to understand the model biases. We note that the model bias does not affect the seasonal to interannual variability of short rains as shown in the following.

Figure 4 shows the seasonal variability of the short rains index obtained after averaging the model rainfall anomalies over the eastern African region $\left(5^{\circ} \mathrm{S}-5^{\circ} \mathrm{N}\right.$, $\left.35^{\circ}-46^{\circ} \mathrm{E}\right)$. The observed variability of the short rains is derived from the gridded rainfall data by taking the area average over the same domain as that of the model index. The monthly rainfall distribution and its standard deviation are very well comparable with those shown in previous studies (e.g., Hastenrath et al. 1993; Black et al. 2003). By comparing the upper and lower panels of Fig. 4, we also find that the model simulates the seasonal short rains and their variability quite realistically despite a month difference in the peak. Although the amplitude of the long rains is less compared to the observation, this model bias may be neglected here, as the main purpose of the present study is to discuss the short rains. In the following, we focus on the interannual variability of the short rains in relation to the tropical climate variability in the Indo-Pacific sector.

\section{Interannual variability of the short rains}

Previous studies, as discussed in section 1, have shown that the interannual variability of short rains is related to large-scale ocean-atmosphere variability in the Indian Ocean. To show the spatial nature of such correlation, we have plotted in Fig. 5 the correlation between the short rains index and the rainfall anoma- 

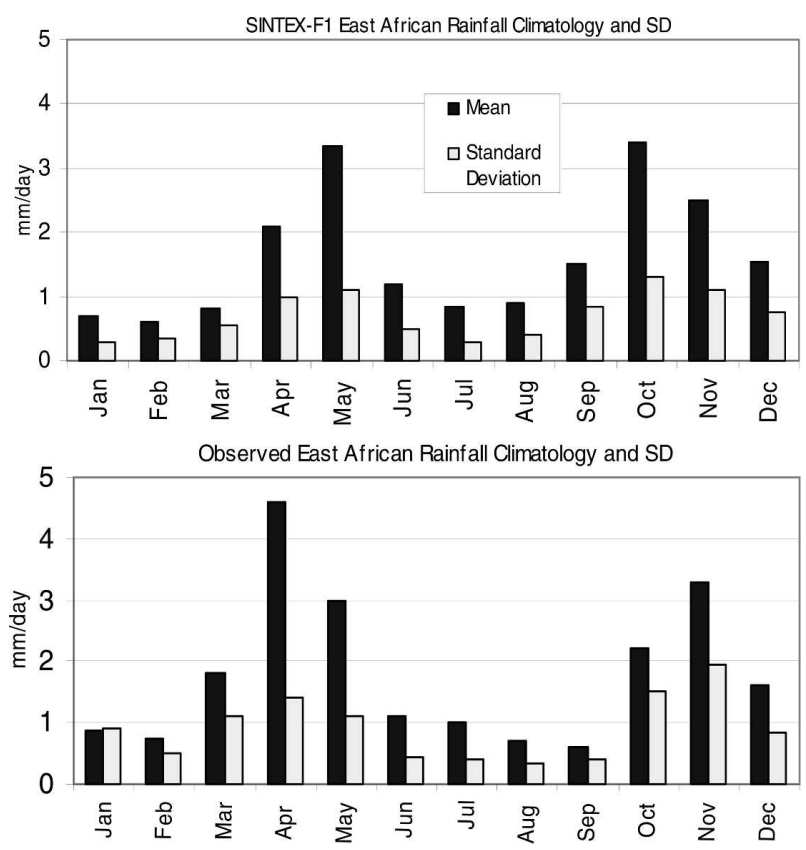

FIG. 4. Climatology of the East African rainfall along with monthly std devs derived from (top) SINTEX-F1 simulation results and (bottom) observation.

lies over the Indian Ocean from the SINTEX-F1 results. Significant correlation coefficients are seen from East Africa to Indonesia. Those coefficients depict a dipole pattern with peak correlation coefficients of 0.7 over East Africa and -0.5 over eastern Indian Ocean. The east-west inverse correlation in the rainfall anomalies is further supported by the associated changes in the atmospheric conditions. Figure 6 shows the correlation between the short rains index and the model ve-

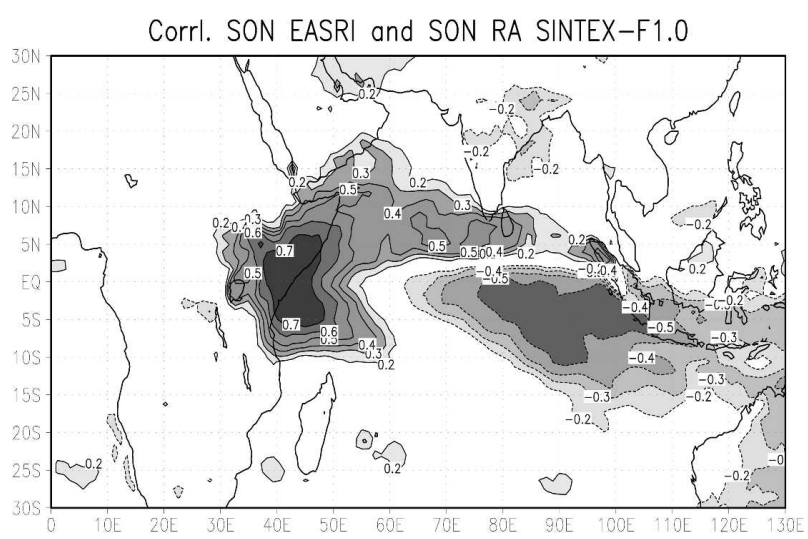

FIG. 5. Correlation of the short rains index with the rainfall anomalies over the Indian Ocean region derived from the SINTEX-F1 simulation results. Shown correlation coefficients are statistically significant at the $99 \%$ confidence level using a two-tailed $t$ test.
Corrl. SON EASRI and SON CHI850, CHI200 SINTEX-F1.0

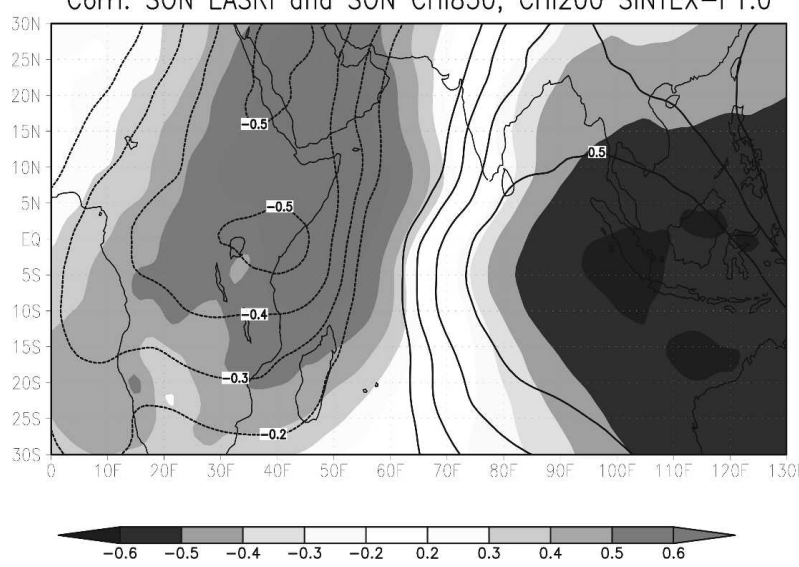

FIG. 6. Same as Fig. 5 but for velocity potentials at 850 (shaded) and $200 \mathrm{hPa}$ (contour). Shown correlation coefficients are statistically significant at the $99 \%$ confidence level using a two-tailed $t$ test.

locity potential anomalies at $850-$ and $200-\mathrm{hPa}$ levels. The east-west dipole with highly significant correlation coefficients on either side of the basin reverse phase between 850 and $200 \mathrm{hPa}$, giving rise to the anomalous Walker circulation. All those are consistent with the observation (Yamagata et al. 2002, 2003) and confirm the link with the IOD simulated in the model.

\section{IOD versus ENSO impact on the short rains}

\section{a. Model IOD and ENSO}

The SINTEX-F1 model, like the SINTEX model (Gualdi et al. 2003), has shown a very good skill in simulating the IOD and ENSO (Behera et al. 2003a; Yamagata et al. 2004). A complete intercomparison of these two sister models along with several others is under preparation. Here we report the salient feature of the SINTEX-F1 in simulating the IOD and ENSO. The model captures the amplitude of the SST variability in the eastern Pacific quite well; the model Niño-3 index standard deviation is $0.8^{\circ} \mathrm{C}$, which is close to the observed standard deviation of $0.87^{\circ} \mathrm{C}$. The model DMI standard deviation is $0.5^{\circ} \mathrm{C}$, which is slightly larger than the observational $0.3^{\circ} \mathrm{C}$ as reported in Saji et al. (1999). We note here that the eastern pole anomalies in the model are seen to spread far more into the central Indian Ocean as compared to observation. Therefore the western box $\left(10^{\circ} \mathrm{S}-10^{\circ} \mathrm{N}, 40^{\circ}-60^{\circ} \mathrm{E}\right)$ used in deriving the model DMI is slightly different from the box $\left(10^{\circ} \mathrm{S}-\right.$ $10^{\circ} \mathrm{N}, 50^{\circ}-70^{\circ} \mathrm{E}$ ) used in Saji et al. (1999) for the observed data. The correlation between the DMI and Niño-3 index is 0.4 for the whole year $(0.51$ for the boreal fall season), which is also quite realistic 
Corrl. SON EASRI and SON SLPA SINTEX-F1

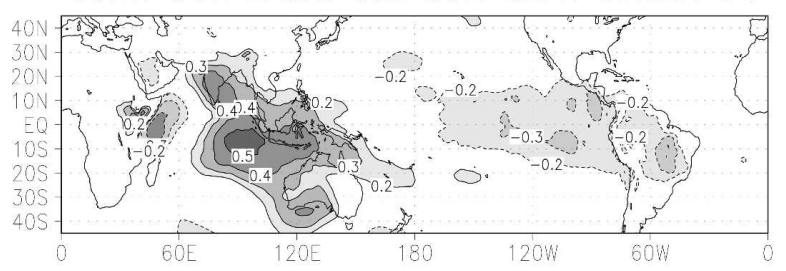

PCorrl. SON EASRI and SON SLPA ENSO Removed

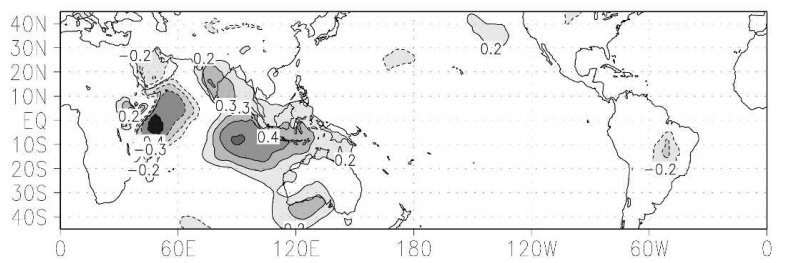

PCorrl. SON EASRI and SON SLPA IOD Removed

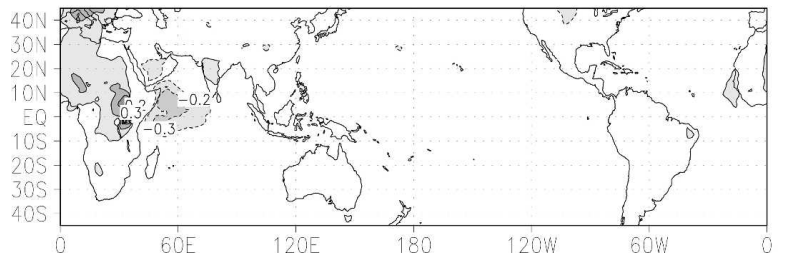

FIG. 7. (top) Correlation between the short rains index and the SLP anomalies from the SINTEX-F1 results. (middle) The corresponding partial correlation between short rains index and SLP anomalies after partialing out the Niño-3 influence. (bottom) The partial correlation between short rains index and global SLP anomalies after partialing out the DMI influence. Shown correlation coefficients are statistically significant at the $99 \%$ confidence level using a two-tailed $t$ test.

(cf. Yamagata et al. 2004). The higher correlation between the two indices for the boreal fall season reflects the nonorthogonal nature of the positive IOD events and warm ENSO events in the model; about $31 \%$ of the total IOD events are associated with warm ENSO events just as in the observation. The ability of the SINTEX-F1 model to reproduce both IOD and ENSO events assures us to go further to examine the IOD and ENSO relation with the short rains.

\section{b. Dominant IOD impact on short rains variability}

Figure 7 shows the correlation between the model short rains index and the model global sea level pressure (SLP) anomalies. The correlation pattern from the simple correlation (top panel of Fig. 7) clearly shows a dipole in the Indian Ocean. The out-of-phase relation between two sides of the basin is consistent with the previous findings. However, we also find the east $\mathrm{Pa}$ cific negative correlation together with the positive correlation in the greater Australasian region, which gives an impression that the short rains is linked to the Southern Oscillation. To shed light on this false attribution, which arises owing to almost one third of positive IOD events co-occurring with warm ENSO events, we have employed a partial correlation technique to segregate the unique association between short rains and IOD from that of short rains and ENSO (Saji and Yamagata 2003b; Yamagata et al. 2004). The middle panel of Fig. 7 shows the correlation partial to IOD. We do not see much difference in the coefficients in those two top panels over the Indian Ocean. However, the coefficients in the eastern Pacific have become insignificant. More interestingly, the correlation partial to ENSO does not show either significant correlation in the $\mathrm{Pa}$ cific or a dipole pattern in the Indian Ocean. Rather the negative correlation coefficients confined to the coastal region in the western Indian Ocean are accompanied by positive correlation over inland Africa. The above exercise confirms that a major portion of interannual variations of the short rains is related to IOD.

Hastenrath et al. (1993) also found the east-west zonal contrast of the SLP anomalies over the Indian Ocean when they correlated the rainfall index of East Africa with the SLP anomalies (October/November correlation plot in their Fig. 10). However, they concluded that changes in the SLP are associated with the phase of SO: During a high SO phase, the Indian summer monsoon tends to be strong leaving behind a cold western Indian Ocean and weaker convection there. In contrast to Hastenrath et al. (1993), we have shown here that the pressure variability in the Indian Ocean related to short rains is not necessarily correlated with the SO. Consequently we did not find any conclusive relationship between the Indian summer monsoon variability and the short rains variability (figure not shown) and therefore the relationship is not discussed further in this study.

To show the observed relationship between the seesaw variation of SLP and the East African rainfall, we have also calculated the correlation between the SLP dipole index and the rainfall anomalies (Fig. 8). Here the SLP dipole index is a difference of SLP anomalies in two boxes of the eastern and western Indian Ocean as defined in Behera and Yamagata (2003). As shown in that study, the SLP dipole index is significantly correlated with the original SST dipole index and the correlation is especially very strong during the boreal fall season. The correlation in Fig. 8 nicely captures a dipole pattern with inverse correlation coefficients over East Africa and Indonesia. The correlation pattern is further examined by using a partial correlation method to establish the relation unique to IOD events. Correlation coefficients that are partial to IOD do not change appreciably in the East African region though a slight decrease in correlation is found in the Indonesian re- 
Corrl. SON SLPDMI Rainfall Data

PCorrl. ENSO Removed

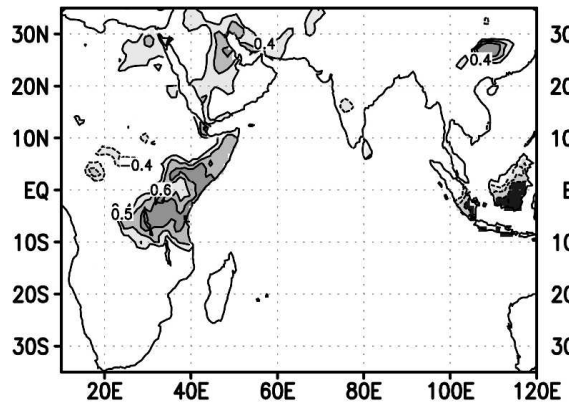

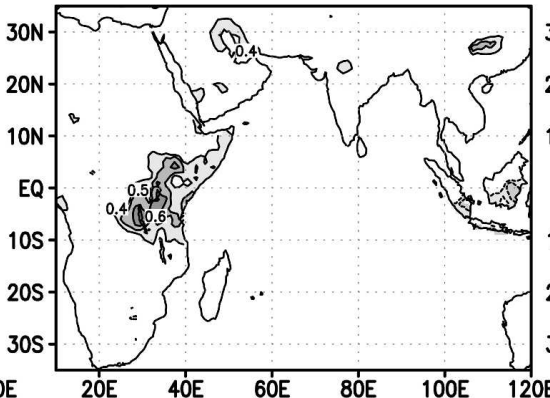

PCorrl. IOD Removed

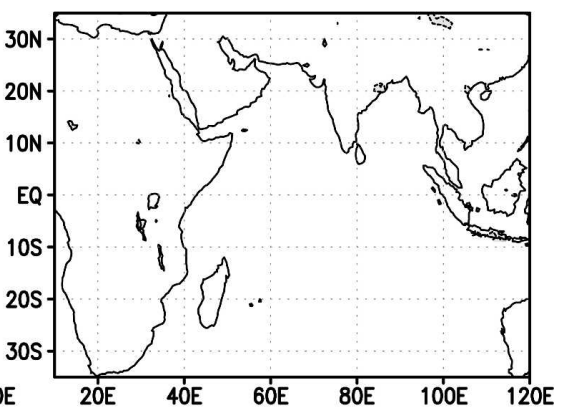

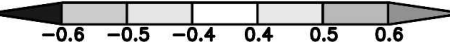

FIG. 8. Same as Fig. 7 but for (left) the correlation between the observed SLP dipole index and the rainfall anomalies. (middle) The corresponding partial correlation after partialing out the Niño-3 influence and (right) the partial correlation after partialing out the DMI influence. Shown correlation coefficients are statistically significant at the $99 \%$ confidence level using a two-tailed $t$ test. The rainfall anomalies for the period 1958 to 1999 are derived from University of Delaware gridded land precipitation analysis, and SLP dipole index was derived from NCEP-NCAR reanalysis data.

gion. In contrast, correlation coefficients that are partial to ENSO did not show any significant values over either sides of the basin. This observational finding is supported by the reverse exercise carried out with SINTEX-F1 simulation results as discussed above; the short rains correlation partial to IOD shows a dipole in the SLP anomalies over the Indian Ocean. Therefore, the pressure variability within the tropical Indian Ocean that causes the East African floods and Indonesian drought is essentially related to the IOD and not necessarily related to the ENSO. If we recognize the fact that the IOD influences the Southern Oscillation through its impact on the Darwin pressure variability (Behera and Yamagata 2003), the present novel relationship between variations in short rains and IOD can be partly reconciled with Hastenrath et al. (1993).

\section{c. Evolution of the IOD-short rains relation}

The evolution of the Indian Ocean conditions in relation to the short rains variability is explored here using a simple correlation analysis. It is evident that the east-west asymmetry in the correlation pattern between the short rains index and SST anomalies evolves from summer as is evident both in the model results and observed data (Figs. 9 and 10). The correlation coefficients in summer, that is, one season before the short rains season, are significant on either sides of the basin. Concurrently we also find a significant negative correlation with the zonal wind anomalies on the equatorial region. The correlation pattern develops into a basinwide dipole in boreal fall; that is, when the peak season of the IOD coincides with the season of short rains. The correlations derived from the model output (Fig. 9) match very well with the observation (Fig. 10; see also Black et al. 2003). The correlations of sea surface height anomalies (Fig. 11) along with the simultaneous high correlation between the short rains index and the zonal wind anomalies emphasizes the existence of oceanatmosphere coupling related to the IOD. This zonal wind correlation corroborates the correlations found in Fig. 6 and confirms the existence of the anomalous Walker circulation reported in Yamagata et al. (2003). The anomalous zonal circulation causes anomalous moisture transport to the western Indian Ocean as found both in the model and observed data (figures not shown). This moisture transport affects low-level stability through changes in the moist static energy, which in turn changes the convective activity over East Africa.

The variability in short rains is not only related to the surface conditions but also related to subsurface conditions of the tropical Indian Ocean. As seen in Fig. 11, the short rains index is found to be highly correlated with the sea surface height anomalies reflecting the subsurface ocean dynamics. Like the correlation with SST anomalies, the correlation between short rains and sea surface height anomalies starts in boreal summer, that is, one season prior to the short rains. The positive correlation patterns south of the equator, which imply the coherent changes in the subsurface heat content, are shown to be associated with the IOD (Rao et al. 2002; Rao and Behera 2005). From the correlations of short rains index, anomalies of sea surface height at different latitude bands and anomalies of wind stress curl it appears that Rossby waves excited by surface winds carry the signal from the central Indian Ocean to 

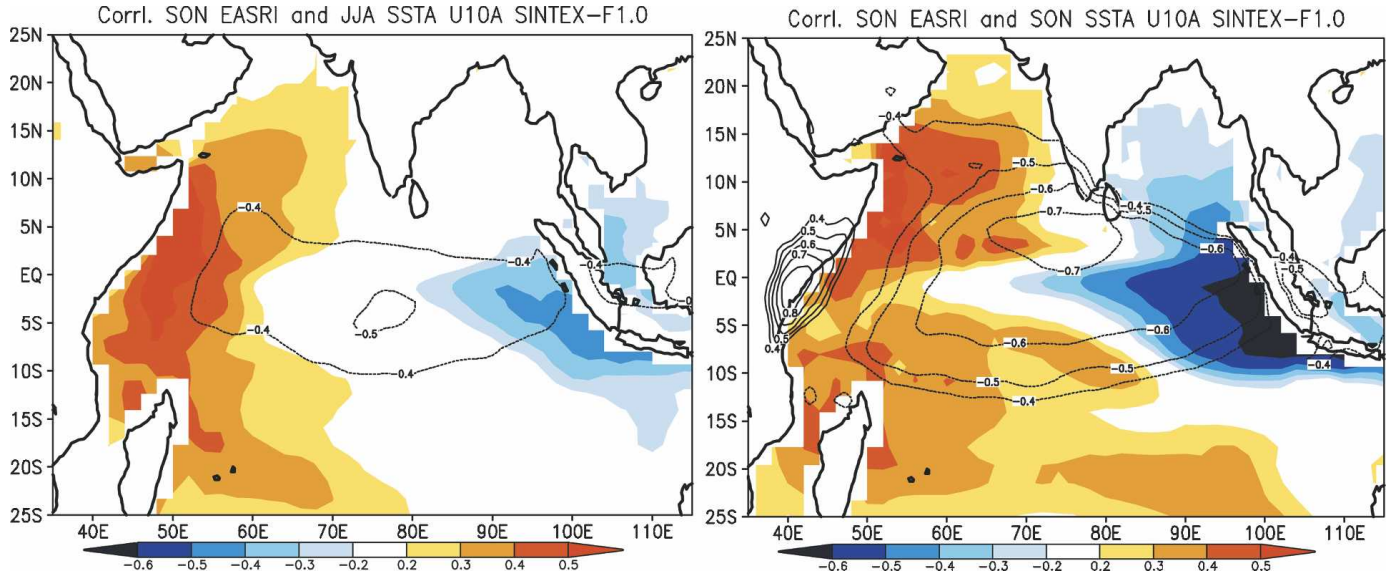

FIG. 9. (left) Lag and (right) concurrent correlations between Sep-Nov short rains index and the anomalies of SST (shaded) and surface zonal winds (contoured) for the Jun-Aug and Sep-Nov seasons computed from the SINTEX-F1 simulation results. Shown correlation coefficients are statistically significant at the $99 \%$ confidence level using a two-tailed $t$ test.

the African coast (figure not shown). The wind forcing has a broader meridional extent in the southern Indian Ocean, which was shown to be associated with ENSO and IOD (Xie et al. 2002). Recent studies (Yamagata et al. 2004; Rao and Behera 2005), however, clarified the exact nature of the forcing by demarcating the region of influence; the dominant forcing for the equatorial Rossby waves is related to the IOD, whereas that for the off-equatorial Rossby waves south of $10^{\circ} \mathrm{S}$ is related to ENSO. During the season of short rains the correlation peaks in the western Indian Ocean on both sides of the equator (Figs. 11 and 12). There is also a strong inverse correlation with equatorial zonal current anomalies, which means the weaker Yoshida-Wyrtki jet during a flood year and vice versa as suggested in the observation (Hastenrath et al. 1993) and ocean model results (Vinayachandran et al. 1999; Murtugudde et al. 2000). Here we find that these correlations agree very well with the analyses of the SODA data (Fig. 12) and the coupled model results (Fig. 11). The above results indicate the possible existence of Bjerknes-type feedback process (Bjerknes 1969) within the Indian Ocean during a flood year in East Africa.

The strong relationship between IOD and short rains is further supported by direct cross-correlation functions between DMI and short rains indices for two consecutive seasons of boreal summer and fall (Table 1). We have also examined the correlation between the zonal wind index of the equatorial Indian Ocean and the short rains index, together with the correlation be-
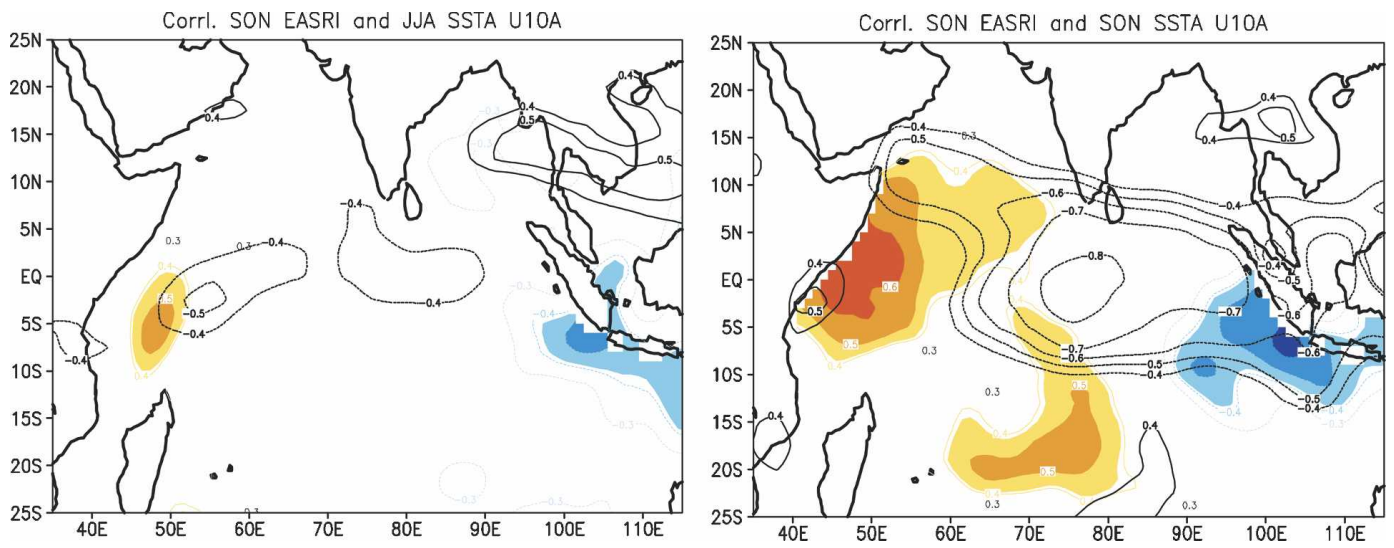

FIG. 10. Same as Fig. 9, but for the observed short rains index and anomalies of SST. The wind anomalies are from the NCEP-NCAR reanalysis data and the SST anomalies are from GISST data. Shaded coefficients for SST anomalies and shown contours for zonal wind anomalies are statistically significant at the $99 \%$ confidence level using a two-tailed $t$ test. 

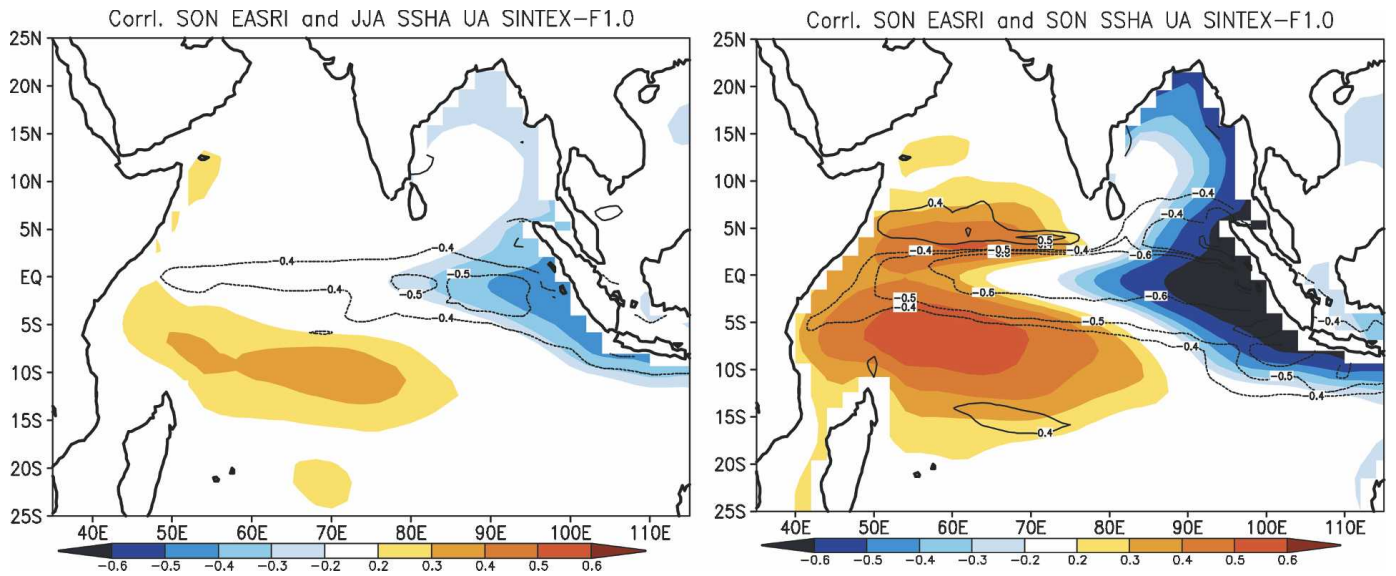

FIG. 11. Same as Fig. 9 but for the anomalies of model sea surface height and surface zonal currents. Shown correlation coefficients are statistically significant at the $99 \%$ confidence level using a two-tailed $t$ test.

tween the short rains index and Niño-3 index for comparison. To determine intrinsic correlation between short rains index and IOD indices, separate from that of the ENSO, we have also shown results based on the partial correlation method. Table 2 compares the correlation coefficients from the model results with those from the observed data. Here all the discussions are related to boreal seasons. The correlation between the DMI and short rains index peaks in boreal fall that coincides with the season of short rains, and is in agreement with previous discussions. The peak correlation in the model is 0.65 , which compares well with a slightly higher observed correlation of 0.7. These coefficients do not change much when the Niño-3 influence is excluded. We find that all coefficients of both simple correlation and partial correlation in the model are comparable to those in the observation. In particular, the lag-correlation between the short rains index and the summer DMI is significant in both model results and observations, suggesting a reasonable skill of DMI in forecasting short rains at least one season ahead. On the contrary, the short rains index does not have any predictive skill for the fall DMI. Also, there is not much contemporaneous correlation between the DMI and East African rain index during boreal summer. This is quite reasonable, considering the season of short rains and variations of the moisture convergence in East Africa, which are mostly outcomes of the IOD evolution. The cross-correlation exercise with the zonal equatorial wind index from the Indian Ocean also supports the above picture; there exists a very high correlation between the short rains index and the zonal wind index during the season of short rains. As expected, the wind index also has a predictive skill one season ahead.

The correlation between the short rains index and the Niño-3 index also peaks during the fall season. The
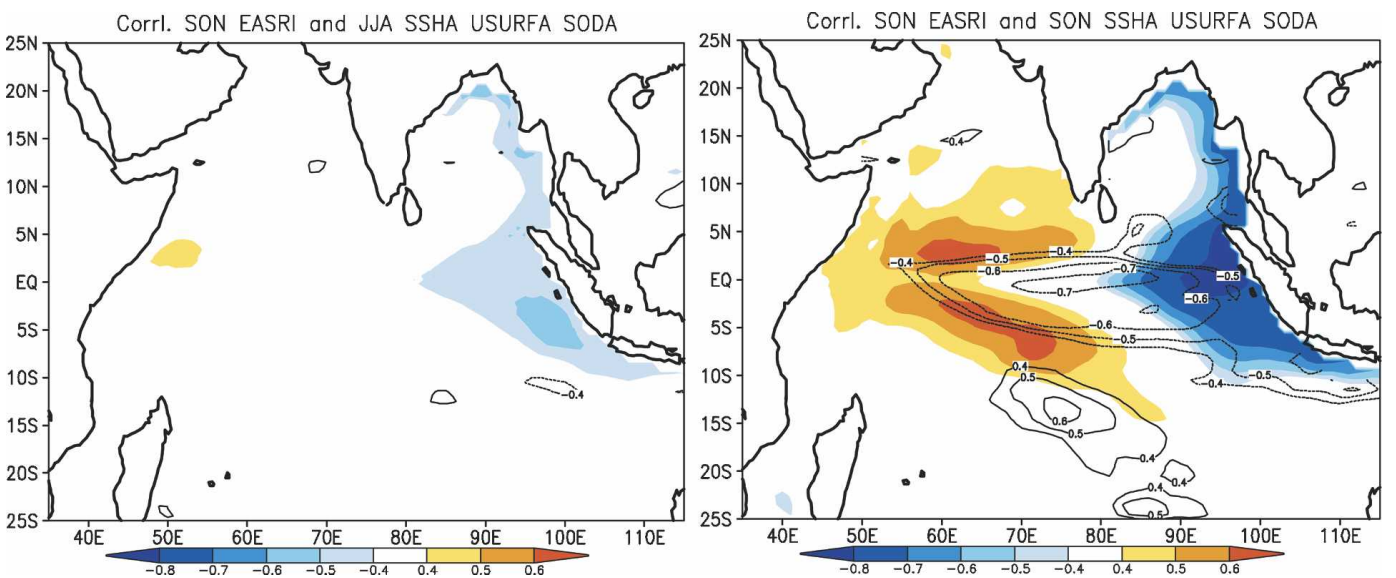

FIG. 12. Same as Fig. 11, but for the anomalies derived from the SODA data. Shown correlation coefficients are statistically significant at the $99 \%$ confidence level using a two-tailed $t$ test. 
TABLE 1. The seasonal cross correlation among the short rains index and the DMI, zonal wind index (UEQ) from the equatorial Indian Ocean, and the Niño-3 from SINTEX-F1 results. The JunAug season is denoted as JJA and the Sep-Nov season is denoted as SON. Values in parentheses are the corresponding partial correlation coefficients. Using the partial correlation method, the Niño-3 influence is excluded from correlations related to both DMI and zonal wind index. The DMI influence is also excluded from the Niño-3 correlations. Values exceeding the $99 \%$ confidence level using a two-tailed $t$ test are shown in bold.

\begin{tabular}{|c|c|c|c|c|c|c|c|}
\hline \multirow{2}{*}{$\frac{\dot{x}}{0} \stackrel{0}{\Xi}$} & & \multicolumn{2}{|c|}{ DMI } & \multicolumn{2}{|c|}{ UEQ } & \multicolumn{2}{|c|}{ Niño-3 } \\
\hline & & JJA & SON & JJA & SON & JJA & SON \\
\hline & JJA & 0.2 & 0 & -0.25 & 0 & -0.2 & -0.23 \\
\hline o & & (0.26) & $(0.2)$ & $(-0.27)$ & $(-0.14)$ & $(-0.21)$ & $(-0.2)$ \\
\hline$\frac{0}{\infty}$ & SON & $\begin{array}{c}0.57 \\
(0.6)\end{array}$ & $\begin{array}{c}0.65 \\
(0.65)\end{array}$ & $\begin{array}{c}-0.5 \\
(-0.47)\end{array}$ & $\begin{array}{l}-0.7 \\
(-0.78)\end{array}$ & $\begin{array}{r}0.34 \\
(0.3)\end{array}$ & $\begin{array}{r}\mathbf{0 . 2 8} \\
(0.2)\end{array}$ \\
\hline
\end{tabular}

simultaneous correlation between them is 0.28 , which is smaller than 0.4 in the observation. However, the correlation coefficients become insignificant when the DMI influence is excluded. We also find that the summer Niño-3 index has a moderate correlation with the fall short rains index. This correlation becomes insignificant in the observation once we exclude the DMI influence but remains weakly significant in the model results. Interestingly we do not find significant correlation with the zonal wind index after excluding the DMI influence (not shown). All the above confirms that the IOD plays a dominant role in the short rains variability and it is well captured by the SINTEX-F1 model. Furthermore, the model's ability to capture the evolution of the anomalous short rains one season ahead is very encouraging in view of predictions.

\section{d. IOD connection with extreme events of short rains}

The statistical correlation method only captures the phase relation between two time series. For better understanding of the nature of IOD and ENSO influences on short rains, it is important to check the amplitude variation particularly during the extreme years (Table $3)$. The anomalous short rains years are categorized as extreme years (flood or drought) when the season's

TABLE 2. Same as Table 1 but for the observed data.

\begin{tabular}{|c|c|c|c|c|c|c|c|}
\hline \multirow{2}{*}{ 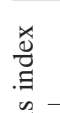 } & & \multicolumn{2}{|c|}{ DMI } & \multicolumn{2}{|c|}{ UEQ } & \multicolumn{2}{|c|}{ Niño-3 } \\
\hline & & JJA & SON & JJA & SON & JJA & SON \\
\hline : & JJA & $\begin{array}{l}024 \\
(026)\end{array}$ & $\begin{array}{l}0 \\
(01)\end{array}$ & $\begin{array}{l}-0.25 \\
(-0.25)\end{array}$ & $\begin{array}{c}0 \\
(-014)\end{array}$ & $\begin{array}{l}-0.02 \\
(-012)\end{array}$ & $\begin{array}{l}-0.18 \\
(0)\end{array}$ \\
\hline 咅 & SON & $\begin{array}{c}(0.26) \\
\mathbf{0 . 5} \\
\mathbf{( 0 . 4 5 )}\end{array}$ & $\begin{array}{c}(0.1) \\
0.7 \\
(0.64)\end{array}$ & $\begin{array}{c}(-0.25) \\
-0.45 \\
(-0.45)\end{array}$ & $\begin{array}{c}(-0.14) \\
-0.8 \\
(-0.8)\end{array}$ & $\begin{array}{c}(-0.12) \\
\mathbf{0 . 3 6} \\
(-0.2)\end{array}$ & $\begin{array}{c}\text { (0) } \\
\mathbf{0 . 4} \\
(0.1)\end{array}$ \\
\hline
\end{tabular}

TABLE 3. Anomalous years of short rains in relation to the DMI years, when either DMI or short rains index exceeds $\pm 1.5 \sigma$. The columns from left to right describe the anomalous years, western pole anomaly, eastern pole anomaly, DMI, short rains index, and Niño-3 index, respectively. Extreme flood and drought years during which the short rains index crosses $\pm 1.5 \sigma$ are shown in bold. All the indices are normalized by their std devs.

\begin{tabular}{lrrrrr}
\hline \hline Years & West & \multicolumn{1}{c}{ East } & \multicolumn{1}{c}{ DMI } & Short rains & Niño-3 \\
\hline $\mathbf{1 9 5 8}$ & $\mathbf{- 0 . 9 8}$ & $\mathbf{0 . 7 2}$ & $\mathbf{- 1 . 3 8}$ & $\mathbf{- 1 . 5 2}$ & $\mathbf{- 0 . 2 8}$ \\
1960 & -1.38 & 1.03 & -1.95 & -0.85 & -0.08 \\
$\mathbf{1 9 6 1}$ & $\mathbf{0 . 8 8}$ & $\mathbf{- 2 . 6 7}$ & $\mathbf{2 . 8 8}$ & $\mathbf{5 . 8 3}$ & $\mathbf{- 0 . 5 4}$ \\
1963 & 1.78 & -1.08 & 2.32 & 0.11 & 1.74 \\
$\mathbf{1 9 6 4}$ & $\mathbf{- 2 . 9 4}$ & $\mathbf{- 1 . 0 3}$ & $\mathbf{- 1 . 5 4}$ & $\mathbf{- 1 . 8 4}$ & $\mathbf{- 1 . 4 6}$ \\
$\mathbf{1 9 6 7}$ & $\mathbf{0 . 8 7}$ & $\mathbf{- 1 . 9 1}$ & $\mathbf{2 . 2 5}$ & $\mathbf{2 . 2 3}$ & $\mathbf{- 1 . 4}$ \\
1970 & -1.54 & 0.47 & -1.63 & -1.46 & -1.66 \\
1971 & -2.86 & -0.64 & -1.8 & -0.59 & -1.21 \\
$\mathbf{1 9 7 2}$ & $\mathbf{3 . 6 9}$ & $\mathbf{- 0 . 0 8}$ & $\mathbf{2 . 9 3}$ & $\mathbf{2 . 1 4}$ & $\mathbf{3 . 6 4}$ \\
1975 & -1.83 & 0.67 & -2.03 & -0.68 & -1.47 \\
$\mathbf{1 9 7 7}$ & $\mathbf{2 . 0 4}$ & $\mathbf{- 0 . 1 6}$ & $\mathbf{1 . 7 8}$ & $\mathbf{1 . 7 7}$ & $\mathbf{0 . 6 6}$ \\
$\mathbf{1 9 8 2}$ & $\mathbf{1 . 5 4}$ & $\mathbf{- 0 . 6 7}$ & $\mathbf{1 . 7 9}$ & $\mathbf{2 . 4 9}$ & $\mathbf{3}$ \\
1986 & -0.08 & -2.23 & 1.75 & -0.58 & 1.85 \\
1994 & 0.26 & -3.83 & 3.32 & 0.78 & 0.46 \\
1995 & 0.02 & 2.22 & -1.79 & -1.28 & -1.61 \\
1996 & -3.07 & 1.21 & -3.47 & -1.41 & -1.04 \\
$\mathbf{1 9 9 7}$ & $\mathbf{1 . 6 2}$ & $\mathbf{- 3 . 6 3}$ & $\mathbf{4 . 2 5}$ & $\mathbf{4 . 9 9}$ & $\mathbf{4 . 8 5}$ \\
1998 & -0.46 & 2.16 & -2.12 & -1.33 & -1.43 \\
\hline
\end{tabular}

rainfall crosses $\pm 1.5 \sigma$ level of the short rains index. This categorization extracts 8 extreme years of short rains during the 41-yr of the available data. The DMI exceeds $1.5 \sigma$ level during all those eight extreme years. An east-west dipole in the SST anomalies is also observed during all the years. The only slight exception is found in 1972 when cooling in the eastern pole is weak. In comparison, we found four ENSO events in which the in-phase Niño-3 index exceeds the $1 \sigma$ level. However, the Niño-3 index was out of phase with the short rains index in 1961 (a record-breaking flood year) and 1967. As a reverse exercise, we have checked whether extreme DMI years exceeding $\pm 1.5 \sigma$ level include anomalous short rains years. These extreme DMI years are shown along with the extreme short rains years in Table 3. In the $41 \mathrm{yr}$ of data, we find 18 extreme DMI years. The extreme DMI years include all extreme short rains years (with a very slight exception in 1958) as expected positive (negative) DMI years correspond to positive (negative) anomalies of short rains except for the year of 1986. Among 18 cases that show significant DMI values, 4 cases in 1964, 1971, 1986, and 1995 are not associated with a dipole pattern; significant DMI values are due to the zonal SST gradient in those cases. The remaining 14 cases confirming to the IOD are associated with the dipole pattern in the SST anomalies. Three of the above four exceptional years: 

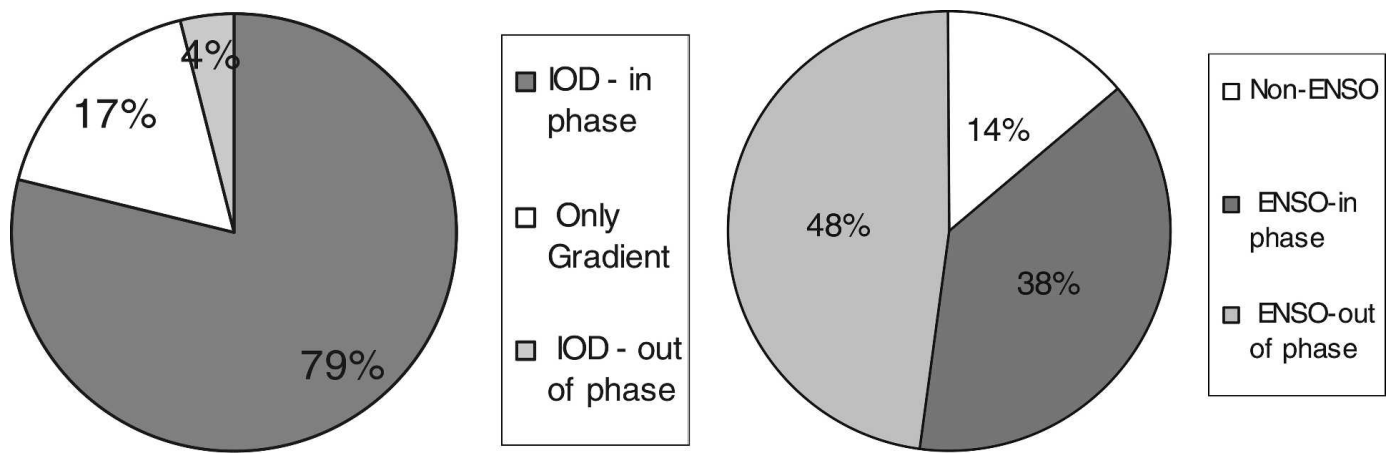

FIG. 13. (left) Pie diagram of the model DMI phase relation with a significant year of short rains. The in-phase relation here means a positive DMI during a flood year and vice versa. The percentage association is derived from a total of 52 extreme years in which the short rains index exceeds the $\pm 1.5 \sigma$ level in the model simulation. (right) The corresponding phase association between the short rains and Niño-3 index. An El Niño event with Niño-3 index above the $0.5 \sigma$ level accompanied by floods in East Africa is considered here as an in-phase event and vice versa.

1964, 1971, and 1995 correspond to La Niña conditions in the Pacific. Since La Niña is expected to influence the Indian Ocean SST through intensifying the normal condition of the Walker circulation owing to enhancement of convection in the western Pacific, the SST dipole structure must be obscured in those years. However, there are still some puzzling cases. One of the extreme DMI years without being associated with the dipole SST pattern, 1986, corresponds to El Niño conditions in the Pacific and is associated with negative short rains anomalies (cf. Clark et al. 2003). One of real dipole years, 1963, corresponds to positive anomalies of the short rains but those are below $0.5 \sigma$ level. Those suggest existence of other secondary players that may influence the short rains.

The above characteristic influence of IOD on short rains anomalies is also evident in the SINTEX-F1 simulation results. It is found that $79 \%$ of years with anomalous short rains $(> \pm 0.5 \sigma$ level $)$ in the model are linked to the IOD (Fig. 13). In addition, 17\% of anomalous years are related to a strong zonal gradient in SST rather than an east-west dipole; this is consistent with the observed $22 \%$. Only $4 \%$ of the extreme cases in short rains are out of phase with the model DMI (flood in spite of a negative DMI and vice versa). Conversely, only $38 \%$ anomalous years of short rains are associated with significant $(>1 \sigma$ level Niño-3 index) in-phase ENSO events in the Pacific (Fig. 13). About $48 \%$ of anomalous years of short rains are associated with outof-phase ENSO events (drought in El Niño and vice versa) and another $14 \%$ of anomalous years are not associated with ENSO events. These analyses not only support results in previous sections but also confirm usefulness of DMI as a predictor for years of extreme short rains.

\section{e. Predictability of anomalous short rains events based on DMI}

In this section we further explore the predictability of the abnormal years of short rains based on the evolving DMI values a few months ahead. The analyses here do not aim to establish a full-fledged statistical model for the short rains prediction as is done by Philippon et al. (2002) but establishes DMI as an effective as well as simple predictor. SST anomalies near the Java and Sumatra coasts evolve during late spring and summer seasons. These anomalies coincide mostly with evolving opposite SST anomalies in the western Indian Ocean, giving rise to an early signal of IOD. The observed data shows that the above normal years of short rains are highly predictable (92\%) using the DMI only in July and August (Fig. 14). There are two exceptional cases; the July (August) indicator predicted erroneously the in-phase anomalous short rains for 1979 (1991). This means that we need both July and August DMI for reliable short rains prediction, possibly to filter out intraseasonal SST variations (cf. Rao and Yamagata 2004).

The SINTEX-F1 also shows similar predictive capacity of the model DMI (Fig. 14). The predictability of a possible abnormal year of short rains is slightly higher in the model even only for August DMI (94\%) as compared to that in the observation. Out of 64 model IOD events, abnormal short rains events failed to occur in only four cases.

We note that extreme years of short rains are rare during the 1980s (Table 3) in accord with weak IOD activities (e.g., Behera and Yamagata 2003). The weakening of the relation between DMI and short rains index during the 1980 s is also reported by Clark et al. 

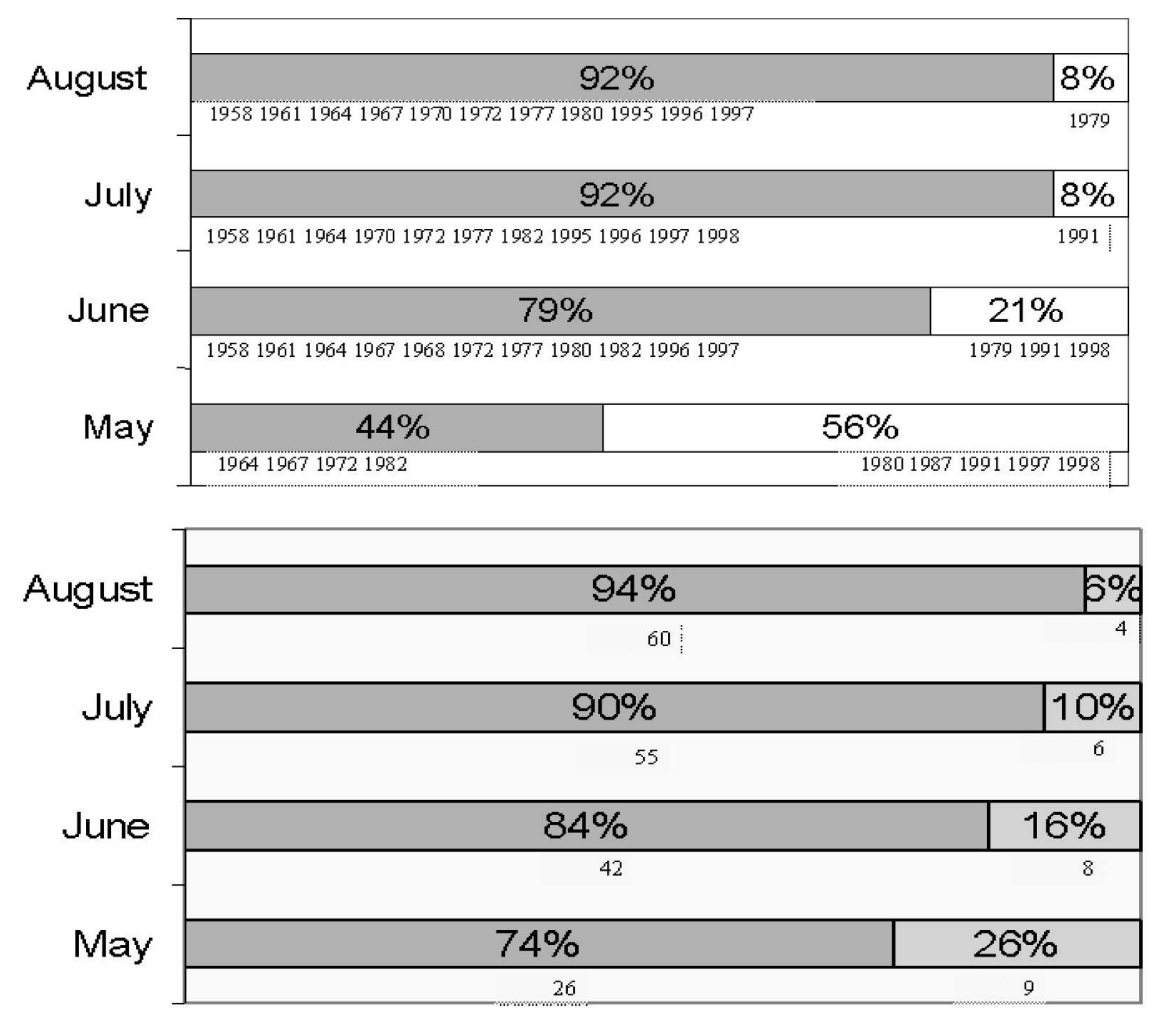

FIG. 14. (top) The percentage skill of the DMI in predicting an abnormal short rains year (short rains index exceeded the $\pm 0.5 \sigma$ level) from the observed data. The percentages of correct predictions are shown in gray shading. The predicted years are shown below each month's skill bar. The correctly predicted years are shown on the left and incorrectly predicted years are shown on the right. The prediction of an out-of-phase anomalous short rains is considered as incorrect prediction and (bottom) the corresponding predictability of the model. The total numbers of years that model DMI predicts correctly (incorrectly) is shown on left (right) side below the skill bar.

(2003). This observed decadal change is also seen in the SINTEX-F1 simulation. We found a clear decline in the model DMI-short rains index correlation around model year 180. As in the observation, this is associated with an exceptional decline of the model IOD activity. To discuss predictability of the anomalous short rains in the long term, we need to pay attention to the decadal/ interdecadal climate variations in the Indo-Pacific sector in addition to annual/interannual climate variations (cf. Ashok et al. 2004; Suzuki et al. 2005, manuscript submitted to J. Phys. Oceanogr.; Tozuka and Yamagata 2003; Tozuka et al. 2005, manuscript submitted to $J$. Climate).

\section{f. The noENSO experiment}

The previous sections reveal the overwhelming impact of IOD on the short rains. It is also shown that the IOD events in model and data are not necessarily associated with the ENSOs. To clarify further the inde- pendent nature of IOD and its impact on short rains, we have analyzed the SINTEX-F1 model results from the noENSO experiment. The standard deviation of the model DMI in this noENSO experiment is 0.44 and model IODs are as realistic as those in the control experiment. Therefore, it is clear that the model IODs are essentially independent of ENSO and the concurrences of IOD and ENSO in certain years are just chance occurrences. This model experiment however does not exclude possibility of interactions between them during the years of co-occurences. Nonetheless, the IOD's paramount impact on short rains did not change significantly in this noENSO experiment results.

Figure 15 shows the correlation between the short rains index and the basinwide rainfall anomalies. As in the control experiment, we see a dipole in the correlation patterns with positive (negative) correlation coefficients in the western Indian Ocean and East African regions (eastern Indian Ocean and Sumatra). The seesaw in the rainfall correlation is further corroborated by 
(a)

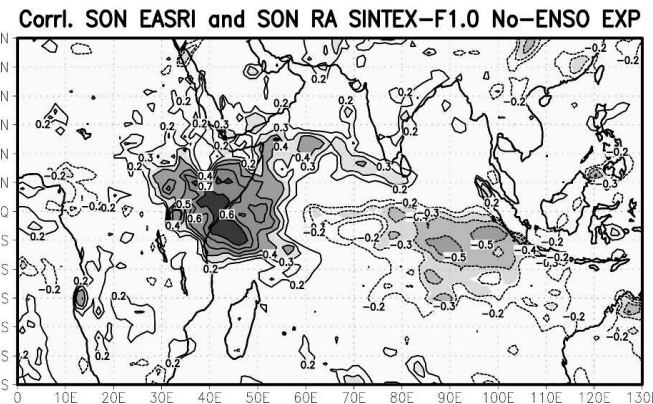

(b)

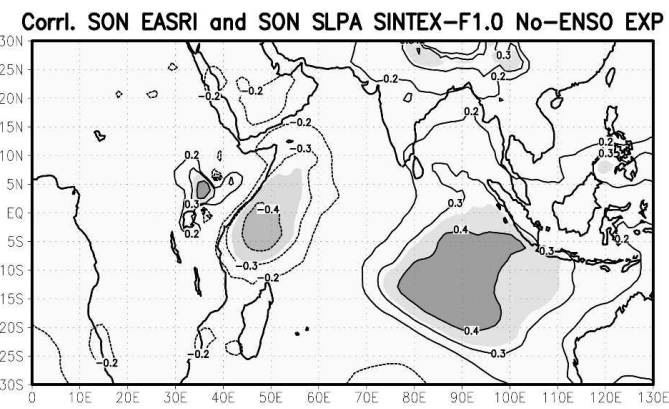

FIG. 15. (a) Same as Fig. 5 but for the noENSO experiment. (b) Same as (a) but for correlation between the short rains index and the SLP anomalies. Shaded correlation coefficients are statistically significant at the $99 \%$ confidence level using a two-tailed $t$ test.

the pattern derived from the correlation between the short rains index and SLP anomalies. The consistency seen between those two correlation plots suggests the robustness of the atmospheric zonal circulation cell within the basin as discussed earlier. The IOD-short rains correlation is also well depicted in the surface and subsurface Indian Ocean. The correlation between the short rains index and the SST anomalies show an eastwest dipole pattern with positive (negative) correlation in western (eastern) Indian Ocean (Fig. 16) as found in the control experiment. The index has also significant inverse correlation with the zonal wind anomalies in the central parts. The ocean-atmosphere coupling process is recognized from the correlation between the short rains index and the heat content anomalies (Fig. 16). In consistent with the SST correlation, the heat content correlation favors the positive influence on the SST. The zonal currents are inversely correlated with the short rains. All those compare well with that of the control experiment. Therefore, it is obvious that the east African short rains are highly correlated to the IOD events independent of ENSO as evident from several of the ocean-atmosphere variables.

These finding of the IOD evolution and the related Indian ocean-atmosphere coupling independent of ENSO are consistent with several previous CGCM studies (e.g., Iizuka et al. 2000; Gualdi et al. 2003; Lau and Nath 2004) but contradicts the findings of BaqueroBernal et al. (2002) and Yu and Lau (2004). Based on their coupled model results and the sensitivity experiments those two studies suggested that model IODs are primarily ENSO forced. An elaborate investigation to (a)

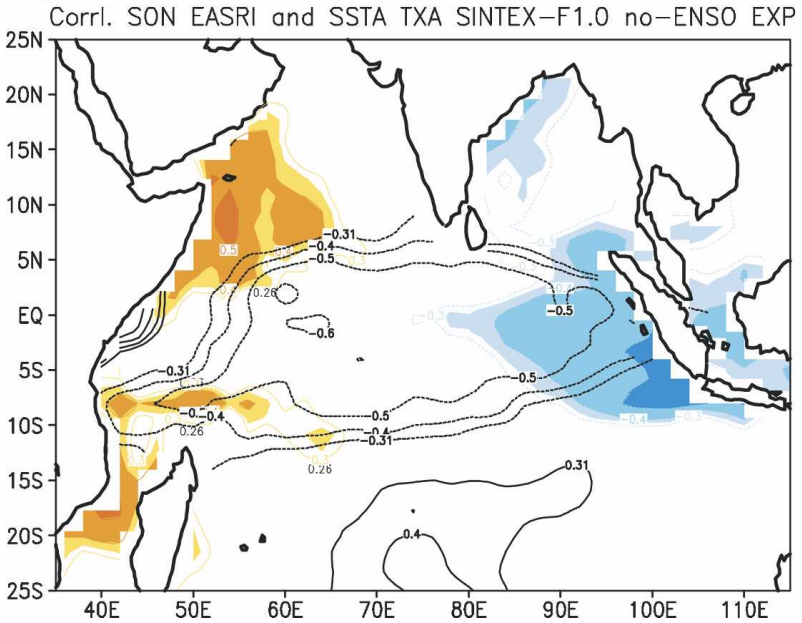

(b)

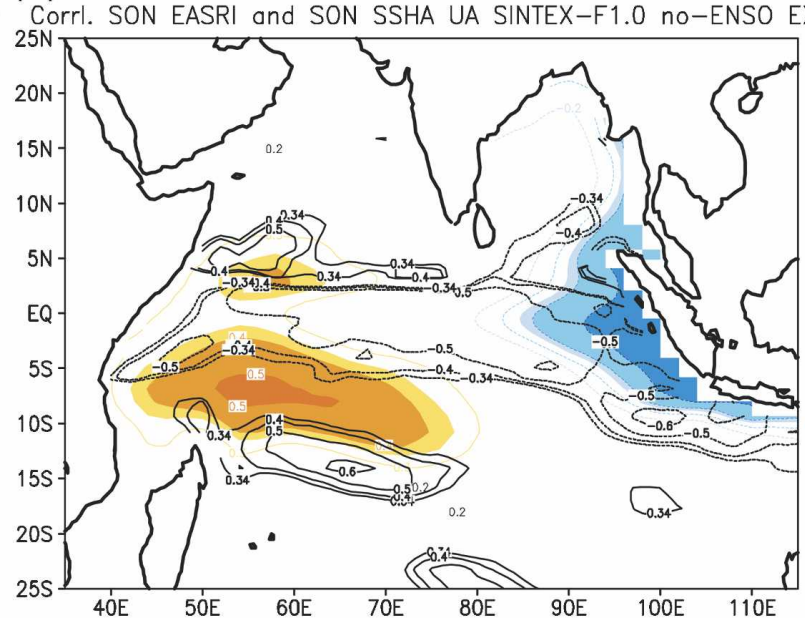

FIG. 16. (a) Same as Fig. 15a but for the correlation between the short rains index and the SST anomalies shown in shading and the correlation between the short rains index and zonal wind anomalies shown in contours. (b) Same as (a) but for the correlation of sea surface height anomalies shown in shading and correlation of surface zonal current anomalies shown in contours. Shaded correlation coefficients for anomalies of SST and sea surface height and shown contours for anomalies of surface zonal wind stress and zonal currents are statistically significant at the $99 \%$ confidence level using a two-tailed $t$ test. 
understand those model biases in resolving independent oceanic processes related to IOD is not within the scope of the present article. Those will be addressed in a separate study.

\section{Discussions and summary}

The ENSO influence on the Indian Ocean has been well documented in the literature. Hastenrath et al. (1993) pointed to the fact that a high SO phase tends to produce a stronger Indian summer monsoon, leaving behind colder SST anomalies near the African coast. The trail is mainly due to variations of the lower tropospheric Findlater Jet. It has been believed that surface cooling (warming) near the African coast following an above (below) normal Indian monsoon year causes below (above) normal short rains. The present analysis has started from doubting the above link among the short rains, Indian summer monsoon, and ENSO. The East African region experienced one of the worst floods of the century during 1961. This event occurred in spite of a normal Pacific condition and a strong Indian summer monsoon. Similarly the floods of east Africa in 1997 occurred during an El Niño but normal Indian summer monsoon condition, and the above normal short rains in 1994 followed not-so-active Pacific condition but with strong Indian summer monsoon condition (Behera et al. 1999).

We have demonstrated that it is possible to explain those abnormal years of short rains once we take into account the intrinsic zonal variability related to IOD; all those years: 1961, 1994, and 1997 are typical IOD years in the Indian Ocean. As found in recent studies (Yamagata et al. 2002, 2004; Saji and Yamagata 2003b; Black et al. 2003; Clark et al. 2003; Behera et al. 2003a), the east-west dipole in the SST anomalies coupled with an anomalous atmospheric zonal circulation cell provides us with the dynamically consistent mechanism for the variability in the short rains.

The ENSO variability in the Pacific is believed to be another driving mechanism for the short rains variability (Clark et al. 2003). This is because the changes in the eastern Pacific SST anomalies induce changes in the Walker circulation and may remotely influence the Indian Ocean SST (Hastenrath et al. 1993; Allan et al. 2001). A detail analysis of the short rains record, however, reveals that a majority of the extreme years are not associated with ENSO in the Pacific as discussed by Saji and Yamagata (2003b). For example, the Niño-3 index was normal during the extreme floods in equatorial eastern Africa in 1961. It was negative during the floods in 1967, above $1 \sigma$ during the scanty rains in 1986 , and weakly positive during the above normal rains in 1994. This observed out-of-phase relationship between short rains and ENSO from a limited observation is well supported in the present study by a 200-yr simulation record of the SINTEX-F1 coupled model; about $48 \%(38 \%)$ of extreme short rains cases occur in absence (presence) of in-phase ENSO events. The SINTEX-F1 model statistics also show that $79 \%$ of the extreme years of short rains correspond to IOD years. It is therefore natural to expect that the atmospheric circulation change associated with the IOD (Yamagata et al. 2003) is a major driver of the anomalous short rains.

The overwhelming influence of the IOD shows up not only in the western Indian Ocean but also in the eastern Indian Ocean. The IOD's domain of influence includes Darwin, and thus IOD affects the Southern Oscillation (Behera and Yamagata 2003). It is therefore understandable that previous studies found a relation between the short rains variability and the Southern Oscillation (Hastenrath et al. 1993). The apparent link of the short rains variability to the out-of-phase Darwin pressure anomaly (in spite of no obvious association with the Tahiti pressure variability) was basically due to the IOD. This is confirmed by not only the short record of the observed data but also from 200-yr long record of the SINTEX-F1 coupled model simulation results.

The early signal of the IOD in the SST dipole mode index is shown here to have a very high prediction skill for the variations of short rains. The prediction of extreme years based on the July and August DMI was successful in $92 \%$ of cases for the observed data. The August predictability might be higher in case of a longer time series of the data. This is implied from the fact that the successful cases increase up to $94 \%$ in case of the SINTEX-F1 model simulation results. The successful prediction of short rains is very important for the regional society (Jury 2002), ranging from reasonable advices for lending money from banks for seed to local management of epidemic diseases (Morse et al. 2003) and flood/drought controls (CLIVAR Africa Report 1999). It is also necessary to understand the decadal/interdecadal nature of the IOD-short rains relation for successful prediction of short rains variability on various time scales as found in both observations and model simulations.

Acknowledgments. Dr. H. Spencer and an anonymous reviewer provided constructive comments that helped in improving the content of the manuscript. Discussions and correspondences with Drs. G. Meyers, B. N. Goswami, J. Slingo, S. A. Rao, N. H. Saji, Y. Masumoto, H. Annamalai, H. Hendon, S. Zebiak, S. Hastenrath, and R. H. Kripalani were very helpful. 


\section{REFERENCES}

Allan, R., and Coauthors, 2001: Is there an Indian Ocean dipole, and is it independent of the El Niño-Southern Oscillation? CLIVAR Exchanges, Vol. 6, 18-22.

Anderson, D. L. T., 1999: Extremes in the Indian Ocean. Nature, 401, 337-338.

Ashok, K., Z. Guan, and T. Yamagata, 2001: Impact of the Indian Ocean dipole on the decadal relationship between the Indian monsoon rainfall and ENSO. Geophys. Res. Lett., 28, 44994502.

—-, W. Chan, T. Motoi, and T. Yamagata, 2004: Decadal variability of the Indian Ocean dipole. Geophys. Res. Lett., 31, L24207, doi:10.1029/2004GL021345.

Baquero-Bernal, A., M. Latif, and S. Legutke, 2002: On dipolelike variability in the tropical Indian Ocean. J. Climate, 15, $1358-1368$

Behera, S. K., and T. Yamagata, 2003: Influence of the Indian Ocean dipole on the Southern Oscillation. J. Meteor. Soc. Japan, 81, 169-177.

—_, R. Krishnan, and T. Yamagata, 1999: Unusual oceanatmosphere conditions in the tropical Indian Ocean during 1994. Geophys. Res. Lett., 26, 3001-3004.

_- J.-J. Luo, S. Masson, T. Yamagata, P. Delecluse, S. Gualdi, and A. Navarra, 2003a: Impact of the Indian Ocean dipole on the East African short rains: A CGCM study. CLIVAR Exchanges, Vol. 27, 43-45.

— S. A. Rao, H. N. Saji, and T. Yamagata, 2003b: Comments on "A cautionary note on the interpretation of EOFs." $J$. Climate, 16, 1087-1093.

Bjerknes, J., 1969: Atmospheric teleconnections from the equatorial Pacific. Mon. Wea. Rev., 97, 163-172.

Black, E., J. Slingo, and K. R. Sperber, 2003: An observational study of the relationship between excessively strong short rains in coastal East Africa and Indian Ocean SST. Mon. Wea. Rev., 131, 74-94.

Carton, J. A., G. Chepurin, X. Cao, and B. S. Giese, 2000: A simple ocean data assimilation analysis of the global upper ocean 1950-1995. Part 1: Methodology. J. Phys. Oceanogr., 30, 294-309.

Clark, C. O., P. J. Webster, and J. E. Cole, 2003: Interdecadal variability of the relationship between the Indian Ocean zonal mode and East African coastal rainfall anomalies. $J$. Climate, 16, 548-554.

CLIVAR Africa Report, 1999: Climate research for Africa. WCRP Informal Rep. 16/1999, ICPO Publication Series 29, $79 \mathrm{pp}$.

Feng, M., G. Meyers, and S. Wijffels, 2001: Interannual upper ocean variability in the tropical Indian Ocean. Geophys. Res. Lett., 28, 4151-4154.

Gualdi, S., E. Guilyardi, A. Navarra, S. Masina, and P. Delecluse, 2003: The interannual variability in the tropical Indian Ocean as simulated by a CGCM. Climate Dyn., 20, 567-582.

Guan, Z., and T. Yamagata, 2003: The unusual summer of 1994 in East Asia: IOD teleconnections. Geophys. Res. Lett., 30, 1544, doi:10.1029/2002GL016831.

Guilyardi, E., G. Madec, and L. Terray, 2001: The role of lateral ocean physics in the upper ocean thermal balance of a coupled ocean-atmosphere GCM. Climate Dyn., 17, 589-599.

Hastenrath, S., and D. Polzin, 2003: Circulation mechanisms of climate anomalies in the equatorial Indian Ocean. Meteor. Z., 12, 81-93.
- A. Nicklis, and L. Greischar, 1993: Atmospherichydrospheric mechanisms of climate anomalies in the western equatorial Indian Ocean. J. Geophys. Res., 98, 20219 20235 .

Iizuka, S., T. Matsuura, and T. Yamagata, 2000: The Indian Ocean SST dipole simulated in a coupled general circulation model. Geophys. Res. Lett., 27, 3369-3372.

Jury, R. M., 2002: Economic impacts of climate variability in South Africa and development of resource prediction models. J. Appl. Meteor., 41, 46-55.

Kalnay, E., and Coauthors, 1996: The NCEP/NCAR 40-Year Reanalysis Project. Bull. Amer. Meteor. Soc., 77, 437-471.

Lau, N.-C., and M. J. Nath, 2004: Coupled GCM simulation of atmosphere-ocean variability associated with zonally asymmetric SST changes in the tropical Indian Ocean. J. Climate, 17, 245-265.

Legates, D. R., and C. J. Willmott, 1990: Mean seasonal and spatial variability in gauge-corrected, global precipitation. Int. $J$. Climatol., 10, 111-127.

Luo, J.-J., S. Masson, S. Behera, P. Delecluse, S. Gualdi, A. Navarra, and T. Yamagata, 2003: South Pacific origin of the decadal ENSO-like variation as simulated by a coupled GCM. Geophys. Res. Lett., 30, 2250, doi:10.1029/2003GL018649.

Madec, G., P. Delecluse, M. Imbard, and C. Levy, 1998: OPA version 8.1 ocean general circulation model reference manual. Tech. Rep./Note 11, LODYC/IPSL, 91 pp.

Masson, S. , and Coauthors, 2005: Impact of barrier layer on winter-spring variability of the southeastern Arabian Sea. Geophys. Res. Lett., 32, L07703, doi:10.1029/2004GL021980.

Morse, A. P., M. B. Hoshen, F. D. Reyes, and M. C. Thomson, 2003: Towards forecasting epidemics in Africa-The use of seasonal forecasting. CLIVAR Exchanges, Vol. 27, 50-52.

Murtugudde, R. G., J. P. McCreary, and A. J. Busalacchi, 2000: Oceanic processes associated with anomalous events in the Indian Ocean with relevance to 1997-1998. J. Geophys. Res., 105, 3295-3306.

Mutai, C. C., and M. N. Ward, 2000: East African rainfall and the tropical circulation/convection on intraseasonal to interannual time scales. J. Climate, 13, 3915-3939.

Ogallo, L. J., 1988: Relationship between seasonal rainfall in East Africa and the Southern Oscillation. J. Climatol., 8, 31-43.

_ J. E. Janowiak, and M. S. Halpert, 1988: Teleconnection between seasonal rainfall over East Africa and global surface temperature anomalies. J. Meteor. Soc. Japan, 66, 807-821.

Philippon, N., P. Camberlin, and N. Fauchereau, 2002: Empirical predictability study of October-December East African rainfall. Quart. J. Roy. Meteor. Soc., 128, 2239-2256.

Rao, S. A., and T. Yamagata, 2004: Abrupt termination of Indian Ocean dipole events in response to intraseasonal disturbances. Geophys. Res. Lett., 31, L19306, doi:10.1029/ 2004GL020842.

-, and S. K. Behera, 2005: Subsurface influence on SST in the tropical Indian Ocean structure and interactions. Dyn. Atmos. Ocean, 39, 103-135.

_ S. K. Behera, Y. Masumoto, and T. Yamagata, 2002: Interannual variability in the subsurface tropical Indian Ocean with a special emphasis on the Indian Ocean dipole. DeepSea Res., 49B, 1549-1572.

Rayner, N. A., E. B. Horton, D. E. Parker, C. K. Folland, and R. B. Hackett, 1996: Version 2.2 of the Global Sea-Ice and Sea Surface Temperature data set, 1903-1994. Climate Research Tech. Note 74, U.K. Met Office, 21 pp. 
Reverdin, G., D. L. Cadet, and D. Gutzler, 1986: Interannual displacements of convection and surface circulation over the equatorial Indian Ocean. Quart. J. Roy. Meteor. Soc., 112, 43-67.

Roeckner, E., and Coauthors, 1996: The atmospheric general circulation model ECHAM4: Model description and simulation of present day climate. Max-Plank-Institut für Meteorologie Rep. 218, Hamburg, Germany, 90 pp.

Ropelewski, F., and M. S. Halpert, 1987: Global and regional scale precipitation patterns associated with the El Niño/Southern Oscillation. Mon. Wea. Rev., 115, 1602-1626.

Saji, H. N., and T. Yamagata, 2003a: Structure of SST and surface wind variability in COADS observations during IOD years. $J$. Climate, 16, 2735-2751.

$\longrightarrow$, and — 2003b: Interference of teleconnection patterns generated from the tropical Indian and Pacific Oceans. Climate Res., 25, 151-169.

— B. B. Goswami, P. N. Vinayachandran, and T. Yamagata, 1999: A dipole mode in the tropical Indian Ocean. Nature, 401, 360-363.

Shinoda, T., M. A. Alexander, and H. H. Hendon, 2004: Remote response of the Indian Ocean to interannual SST variations in the tropical Pacific. J. Climate, 17, 362-372.

Tozuka, T., and T. Yamagata, 2003: Annual ENSO. J. Phys. Oceanogr., 33, 1564-1578.

Valcke, S., L. Terray, and A. Piacentini, 2000: The OASIS coupler user guide version 2.4. Tech. Rep. TR/CMGC/00-10, CERFACS, Toulouse, France, 85 pp.

Vinayachandran, P. N., N. H. Saji, and T. Yamagata, 1999: Response of the equatorial Indian Ocean to an anomalous wind event during 1994. Geophys. Res. Lett., 26, 1613-1616.
Webster, P. J., A. Moore, J. Loschnigg, and M. Leban, 1999: Coupled ocean-atmosphere dynamics in the Indian Ocean during 1997-98. Nature, 401, 356-360.

Willmott, C. J., and K. Matsuura, 1995: Smart interpolation of annually averaged air temperature in the United States. $J$. Appl. Meteor., 34, 2557-2586.

Xie, S.-P., H. Annamalai, F. Schott, and J. P. McCreary, 2002: Structure and mechanisms of south Indian Ocean climate variability. J. Climate, 15, 864-878.

Yamagata, T., S. K. Behera, S. A. Rao, Z. Guan, K. Ashok, and H. N. Saji, 2002: The Indian Ocean dipole: A physical entity. CLIVAR Exchanges, Vol. 24, 15-18.

$-,-,-\longrightarrow, \ldots$, and,- 2003 : Comments on "Dipoles, temperature gradient, and tropical climate anomalies." Bull. Amer. Meteor. Soc., 84, 1418-1422.

— — - J.-J. Luo, S. Masson, M. Jury, and S. A. Rao, 2004: Coupled ocean-atmosphere variability in the tropical Indian Ocean. Earth Climate: The Ocean-Atmosphere Interaction, Geophys. Monogr., No. 147, Amer. Geophys. Union, 189212.

Yu, J.-Y., and K. M. Lau, 2004: Contrasting Indian Ocean SST variability with and without ENSO influence: A coupled atmosphere-ocean GCM study. Meteor. Atmos. Phys., doi:10.1007/s00703-00400094-7.

Yule, G. U., 1907: On the theory of correlation for any number of variables treated by a new system of notation. Proc. Roy. Soc., 79A, 182-193.

Zubair, L., S. A. Rao, and T. Yamagata, 2003: Modulation of Sri Lankan Maha rainfall by the Indian Ocean dipole. Geophys. Res. Lett., 30, 1063, doi:10.1029/2002GL015639. 